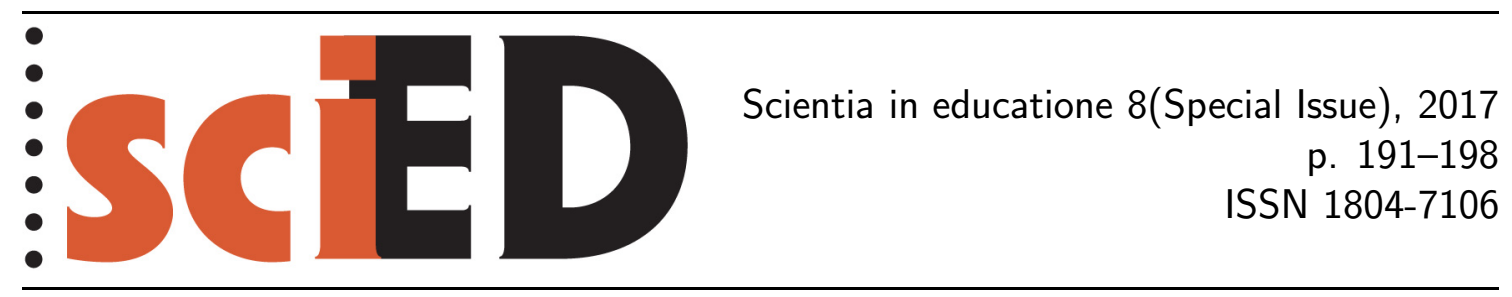

\title{
A Hands-on to Teach Colour Perception: The Colour Vision Tube
}

\author{
Claudia Haagen-Schützenhöfer
}

\begin{abstract}
One basic concept for understanding colour phenomena is the concept of vision. Although vision seems to be quite a natural and simple thing, students are often not familiar with the mechanism behind perceiving objects or even "the colour of objects". This contribution introduces a simple hands-on experiment, the Colour Vision Tube. The Colour Vision Tube facilitates the experience of seeing "coloured" objects illuminated with other than white light sources. These experiences support students in understanding the relevance of the illuminating light and the conception of selective reflection for colour vision.
\end{abstract}

Key words: basic optics, colour, vision. 


\section{INTRODUCTION}

Colour phenomena are usually fascinating. However, it is frequently quite challenging for students to explain such phenomena based on adequate scientific concepts. This contribution focuses on body colour phenomena. After instruction of basic optics, students still believe the colour impression they get from an object is a fixed property of this object. (Andersson \& Kärrqvist, 1983; Driver, Guesne \& Tiberghien, 1985; Fetherstonhaugh \& Treagust, 1992; Viennot \& de Hosson, 2012). Although they are mostly able to reproduce the laws of colour mixing, they can hardly account for colour impressions produced by objects illuminated with other than white light sources. We developed a hands-on experiment, the Colour Vision Tube, which can be easily used in class to demonstrate such colour effects.

\section{TheORETICAL BACKGROUND}

Students' ideas about vision have been investigated thoroughly and show students' difficulties in explaining the visibility of objects based on light emitted by a source and reflected by the object into the observer's visual system (cf. Figure 1, physicists' model).

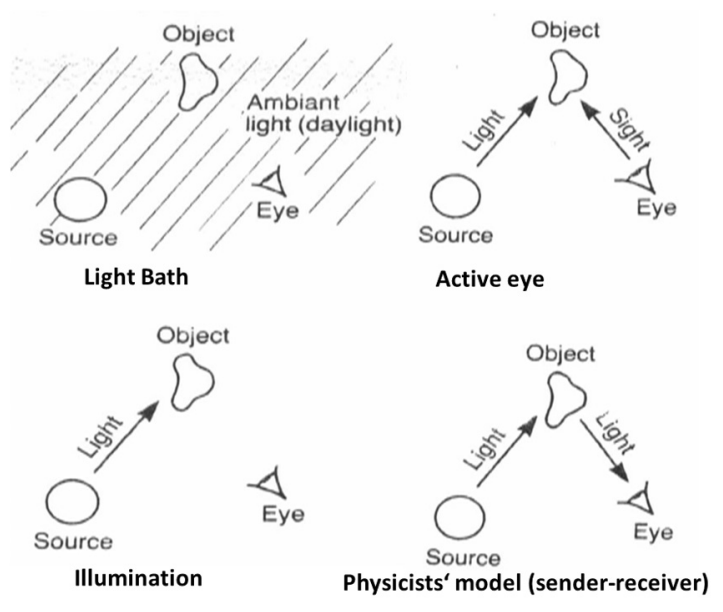

Figure 1: Students' conceptions on vision (categories based on (Guesne, 1985))

Without a basic concept of vision, it seems to be difficult to develop scientifically adequate ideas concerning colour and coloured objects. As a result, it is frequently believed that colour is a fixed property of an object, as mass is for example. Empirical research shows that misconceptions about colour are not only present among students but also among many adults (Martinez-Borreguero et al., 2013).

Feher \& Meyer (1992: p. 505-520) give a summary of the most frequently held conceptions about colour vision:

1. Coloured light mixes with the colour of the object,

2. coloured light is dark and makes the object darker,

3. coloured light gives the colour to the object and

4. coloured light has no effect on the object.

Conventional instruction is usually not successful in transforming these conceptions into adequate physical concepts about vision and colour (Andersson \& Kärrqvist, 1883; Martinez-Borreguero et al., 2013). From conceptual change theory it 


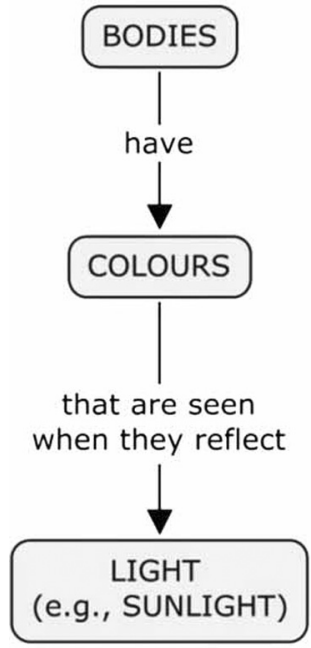

INITIAL CONCEPT MAP

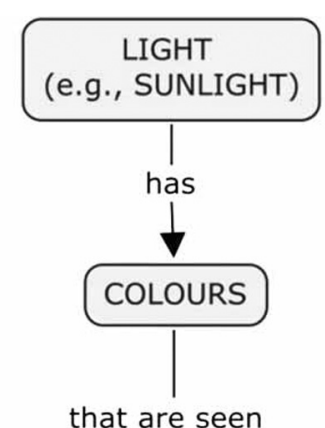

when it is reflected by

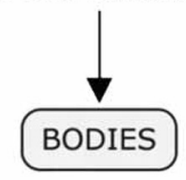

MODIFIED

CONCEPT MAP

Figure 2: Concepts about colour phenomena (left: frequently held student conception; right: "new", scientifically sound concept) (Martinez-Borreguero et al., 2013)

is known that conceptions tend to be extremely stable as they have proved to be viable in daily life in uncountable occasions (Posner et al., 1982). Thus, students do not feel the necessity to change their ideas; they frequently hold the idea that bodies have a permanent colour that can be seen when they are illuminated (cf. Figure 2, left). This theoretical background explains quite well why especially colour issues are difficult for students. In their daily lives they are predominantly in situations where their surroundings are illuminated by some kind of white light sources.

One major issue of discussion within conceptual change is the question how to address students' misconceptions in order to trigger conceptual change. Conceptual change research has not come to empirically grounded solutions on this issue, yet. Posner et al. (1982: p. 211-227), however, suggested a number of broadly accepted requirements characterising new concepts presented to students. To support conceptual change, they recommended that students do not only need to be dissatisfied with their current conceptions but the new conceptions introduced need to be intelligible, plausible, and fruitful. The Colour Vision Tube was thought to provide a variety of evidences that widen students' ideas about colour vision. Their conceptions about colour being a fixed property of an object (cf. Figure 2, left) should be reorganised in the following way: light has colour(s), objects selectively reflect them and the composition of the light received by our visual system creates a certain colour impression (cf. Figure 2, right).

\section{Research Aims \& Questions}

The overall aim of this project was to promote students' understanding of "seeing colours". The main idea was to create a learning environment that makes students familiar with the experience of observing "differently coloured objects" illuminated by differently coloured light. Our intention was to create a hands-on that is easy to construct and also easy to handle in the classroom and above all, a hands-on that functions as learning environment which can be individually manipulated by 
students. The purpose of the evaluation conducted was to analyse learning effects triggered by the use of the Colour Vision Tube. Our main research questions were:

1. Does the use of the Colour Vision Tube promote a sender-receiver model of vision?

2. Does the use of the Colour Vision Tube promote students' understanding of selective absorption and reflection as basic condition for body colour phenomena?

\section{Methods}

A micro-teaching intervention based on the Colour Vision Tube was designed to be used in semi-structured student interviews. The intervention was aimed at students after their basic instruction in optics in year $8^{1}$. The students of our sample $(N=21$, 9 female \& 12 male) were aged 13 to 15 years. They were randomly selected: they had different school carriers and learning histories in physics, were in different types of schools in different areas of Austria. In order to avoid having a sample not representing the "typical Austrian high school student" at this age group, we also wanted to find out about their attitude towards physics and learning of physics. For this purpose we used the concept of self-efficacy in physics - following the scales of PISA 2000. The students of our sample showed a mean self-efficacy in physics $m=2.39^{2}(\mathrm{SD}=0.73)$. This quite well fits the data of the Austrian PISA sample 2000 with a mean self-efficacy of $m=2.37(\mathrm{SD}=0.84)$ (Kunter et al., 2002).

In the first part of the interview the students filled in the PISA scales on selfefficacy and some other general data. Then they were given test items on colour vision (Herdt, 1990). After that they worked with the Colour Vision Tube following the $\mathrm{P}$ (redict) $\mathrm{O}$ (bserve) $\mathrm{E}$ (xplain) structure (White \& Gunstone, 1992). Finally, the students were asked to do some transfer tasks and fill in test items. The interviews were led by trained interviewers.

The data collected from the interviews were analysed concerning the lines of argumentations students used to explain colour phenomena before and after the short POE intervention with the Colour Vision Tube. The categories underlying the analysis were taken from literature. The categories about students' conceptions on colour vision were based on Feher \& Meyer (1992). As we did not find any students' statements relating to the idea that coloured light is dark and makes the object darker, this category was omitted. The categories on conceptions on vision also had to be modified (Guesne, 1985). An additional category "reflection" was created which subsumed all student utterances that mentioned that the disc in the vision tube reflected light, but that did not contain any hints that this reflected light (partly) entered the visual system of the observer.

\section{The intervention with the Colour Vision Tube}

The Colour Vision Tube is a hands-on made of a tube ${ }^{3}$ which is closed at one end with a disc made of differently coloured segments (cf. Figure 3). In the middle of the

\footnotetext{
${ }^{1}$ In the Austrian educational system basic optics (including colour phenomena) is part of the year 8 Physics curriculum. Wave optics is part of the year 10 curriculum.

${ }^{2}$ Self-efficacy runs from 1 to 4.1 stands for high self-efficacy.

${ }^{3}$ The tube is about $25 \mathrm{~cm}$ long and $8 \mathrm{~cm}$ in diameter. It is made of insulating material for heating pipes.
} 
Disc with coloured

boxes inside

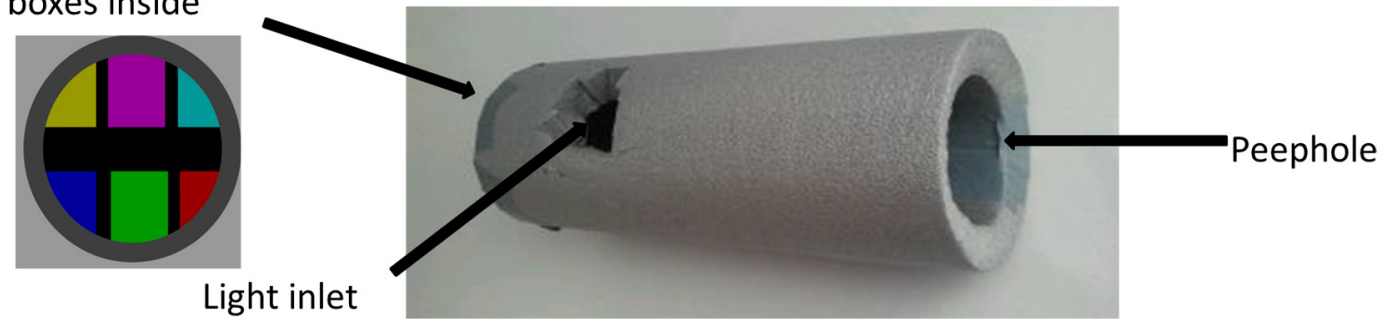

Figure 3: The Colour Vision Tube (CVT)

tube, there is a light inlet just big enough to insert the light source. As light source we used a modified version of the colour mixer by Planinšič (2004: p. 138), a quite easy to build device based on RGB colour addition of LEDs. The open end of the tube serves as peephole for the observer. When students look through this peephole while the tube is illuminated with differently coloured LEDs, they can experience the effect of different illumination on the "body colour" they perceive.

During the intervention phase with the Colour Vision Tube, the students had to work successively on two predictions:

1. What will happen if we block the hole? (first POE cycle)

2. What will happen if we illuminate the Colour Vision Tube with red light? (second POE cycle)

The first prediction cycle was meant to initiate learning processes on a physical concept of vision based on a sender-receiver model (cf. Figure 1). The second cycle was based on the idea that the "colour of an illuminated object" depends on the illuminant. So after observing the Colour Vision Tube illuminated with red light, the students had the opportunity to explore the effects of differently coloured illuminants (cf. Figure 4).
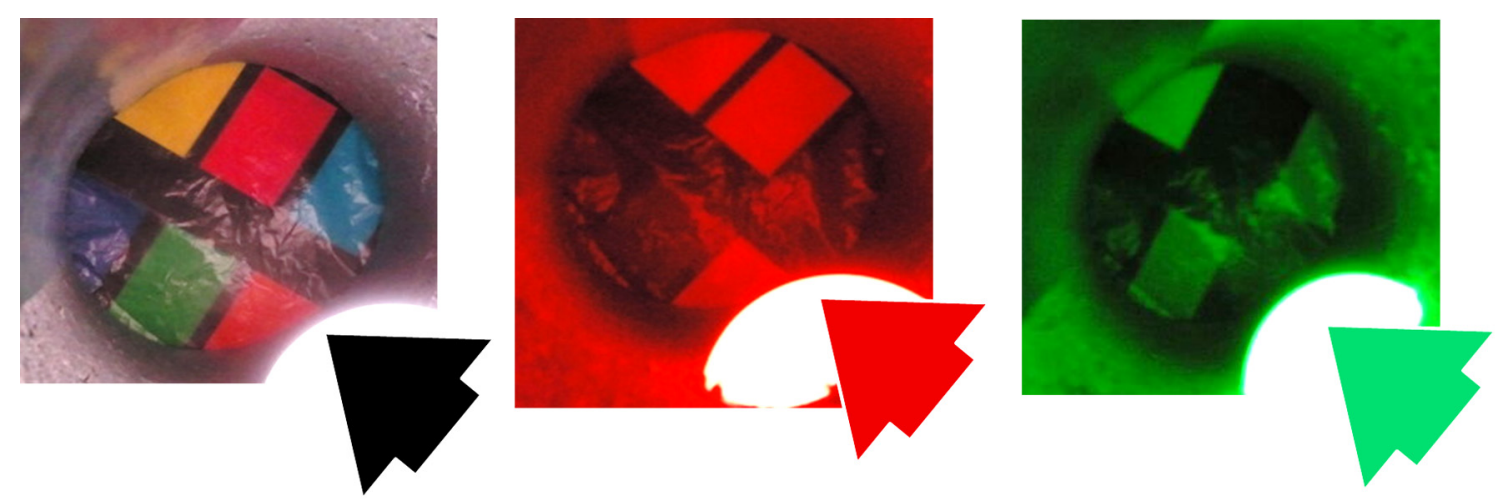

Figure 4: The inside of the Colour Vision Tube illuminated with white, red and green light

\section{SELECTED RESULTS}

The data collected during the first POE cycle showed that the majority of students firstly used common sense arguments to explain why they were able to see the coloured disc at the end of the tube only as long as the light inlet was not blocked. Most students used the concept of illumination without considering the necessity of 


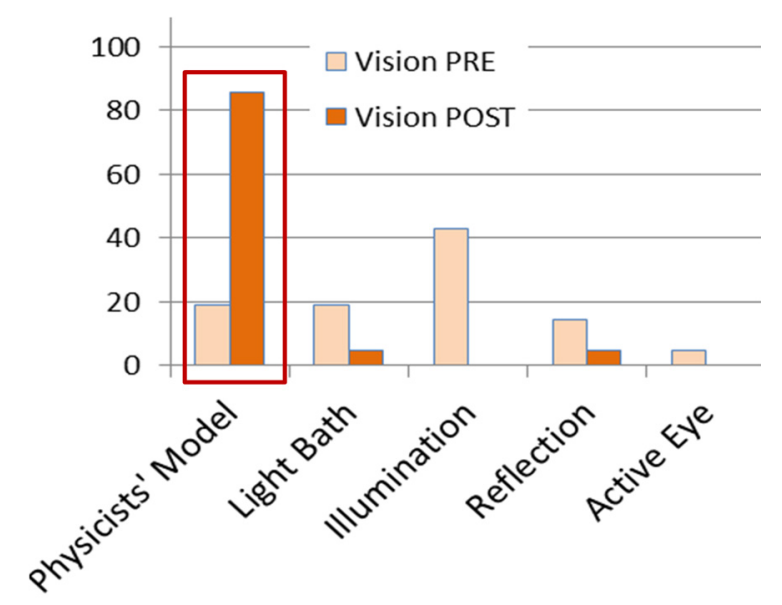

Figure 5: Students' ideas concerning vision before and after the CVT-intervention in percent

light from the disc entering the eye of the observer (cf. Figure 5). After the first POE cycle the majority of the students did not only know that light is necessary for vision, but they also identified the light source (the illuminant), the illuminated object and the eye (receiver) as essential components for vision.

The second POE cycle focused on colour vision, on the apparent colour of objects illuminated with light sources other than white. Most students initially believed that either the colour of the illuminant or a mixture of the colour of the illuminant and the colour of the illuminated object was responsible for the colour they perceived (cf. Figure 6). Only a minority of students held the conception that selective reemission determines the perceived colour. Similarly, the idea that the apparent colour of an object stays the same independently of the colour of the illuminant, was rarely mentioned.

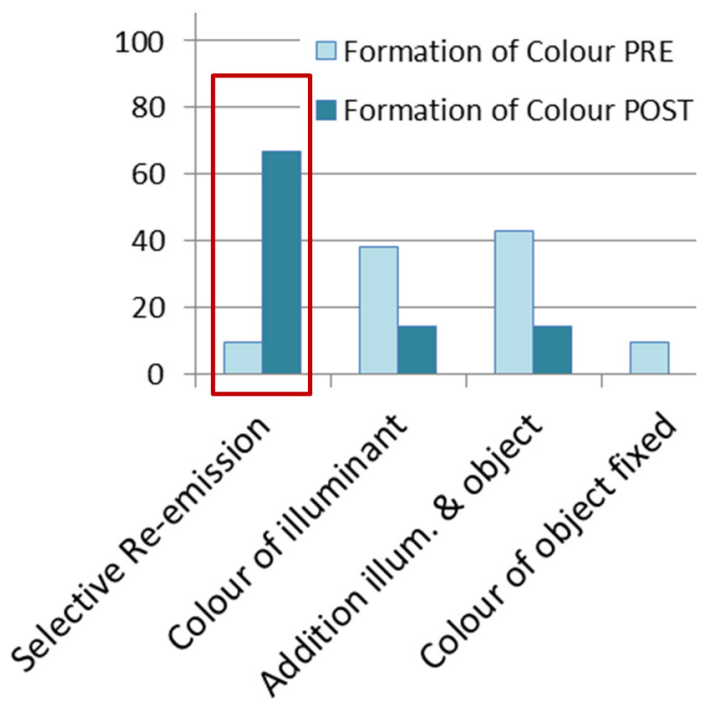

Figure 6: Students' ideas concerning colour vision before and after the CVT-intervention in percent

After the second POE cycle, about two thirds of the students were able to apply the idea that colour impression is not a consequence of the property of objects but a consequence of the interaction between an object and the light illuminating this object (cf. Figure 6). However, a closer analysis showed that they had problems 
when primary colours of subtractive and additive colour mixing were used at the same time. For example it was easy for them to use the RGB scheme to explain why the blue and green segments ${ }^{4}$ of the disc appear to be black when using a red illuminant. On the other hand, most students were not able to account for the fact that yellow and magenta segments ${ }^{5}$ appear to be reddish when illuminated with red light, while cyan segments appear to be black.

\section{SUMMARY \& CONCLUSIONS}

The hands-on we called "Colour Vision Tube" (CVT) is easy to build. Its use in class turned out to be simple and effective. Observations with the CVT support students in experiencing colour characteristics of an illuminated object with varying illuminants (ranging from no illumination at all to white and differently coloured light).

In the prediction-stages of our intervention, most students were not able to verbalize the process of vision based on a physical correct model, nor were they able to explain the physical process of seeing colours adequately. After reinforcing a physicit's model of vision in the first POE cycle, students could experience the effect of different light colours on their perception of objects in a second POE cycle.

They are used to judging the "colour of an object" when illuminated by sunlight or similar light. The lacking experience of illuminants with different colour characteristics seems to hinder students to internalize the concept that colour is not a physical property of an object, but depends on how an object reflects light that reaches it.

The use of the CVT gives students the opportunity to experience the effects of changing light colour on the reflecting behaviour of objects. This seems to support students in developing a relationship between their visual colour sensation, the colour characteristic of an illuminant and the reflection behaviour of the illuminated object.

\section{REFERENCES}

Andersson, B. \& Kärrqvist, C. (1983). How Swedish pupils, aged 12-15 years, understand light and its properties. International Journal of Science Education, 5(4), $387-402$.

Driver, R., Guesne, E. \& Tiberghien, A. (1985). Children's ideas in science.

Buckingham: Open University Press.

Feher, E. \& Meyer, K. (1992). Children's conceptions of color. Journal of research in Science Teaching, 29(5), 505-520.

Fetherstonhaugh, T. \& Treagust, D. (1992). Students' understanding of light and its properties: Teaching to engender conceptual change. Science Education, 76(6), 653-672.

Guesne, E. (1985). Light. In R. Driver, E Guesne, \& A. Tiberghien (Eds.), Children's ideas in science (10-32). Buckingham: Open University Press.

\footnotetext{
${ }^{4}$ To be more precise: the segments of the disc which appear blue and green when illuminated with white light.

${ }^{5}$ To be more precise: the segments of the disc which appear yellow and magenta when illuminated with white light.
} 
Herdt, D. (1990). Einführung in die elementare Optik. Vergleichende Untersuchung eines neuen Lehrgangs. Essen: Westarp-Wissenschaftsverlag.

Kunter, M., Schümer, G., Artelt, C., Baumert, J., Klieme, E., Neubrand, M., Prenzel, M., Schiefele, U., Schneider, W., Stanat, P., Tillmann, K.-J. \& Weiß, M. (2002). PISA 2000: Dokumentation der Erhebungsinstrumente. Max-Planck-Inst. für Bildungsforschung.

Martinez-Borreguero, G., Pérez-Rodríguez, Á. L., Suero-López, M. I. \& Pardo-Fernández, P. J. (2013). Detection of misconceptions about colour and an experimentally tested proposal to combat them. International Journal of Science Education, 35(8), 1299-1324.

Planinšič, G. (2004). Color mixer for every student. The Physics Teacher, 42, 138-142.

Posner, G., Strike, K., Hewson, P. \& Gertzog, W. (1982). Accommodation of a scientific conception: Toward a theory of conceptual change. Science Education, 66(2), 211-227.

Viennot, L. \& de Hosson, C. (2012). Beyond a dichotomic approach, the case of colour phenomena. International Journal of Science Education, 34(9), 1315-1336.

White, R. \& Gunstone, R. (1992). Probing understanding. Routledge.

Claudia HAaGen-SCHÜtZENHÖFER

Institute of Physics, Didactics of Physics, University of Graz, Graz, Austria 